\title{
Echocardiographic assessment of mitral durability in the late period following mitral valve repair: Minithoracotomy versus conventional sternotomy
}

Jae Suk Yoo, MD, Joon Bum Kim, MD, PhD, Sung-Ho Jung, MD, PhD, Suk Jung Choo, MD, PhD, Cheol Hyun Chung, MD, PhD, and Jae Won Lee, MD, PhD

Objective: To compare the long-term echocardiographic mitral valve (MV) durability after MV repair performed through a minithoracotomy versus conventional sternotomy.

Methods: A total of 299 patients who underwent MV repair for degenerative mitral regurgitation (MR) through minithoracotomy $(n=179)$ or sternotomy $(n=120)$, between April 2004 and January 2010, were evaluated. To adjust the differences in baseline characteristics between the 2 groups, weighted Cox proportional-hazards regression models and inverse-probability-of-treatment weighting were used.

Results: There were no 30-day deaths in both groups and no significant differences in early complication rates. Clinical follow-up was complete in 294 patients $(98.3 \%$ ), with a median follow-up of 55.4 months (interquartile range, 34.4-66.9 months), during which there were 10 late deaths, 2 strokes, and 3 reoperations for recurrent MR. After adjustment, the minithoracotomy group had similar risks for major adverse cardiac events (hazard ratio, $0.77 ; 95 \%$ confidence interval, $0.22-2.68 ; P=.68)$. Echocardiographic evaluation in the late period $(>6$ months $)$ was possible in 292 patients (97.7\%), with a median follow-up of 29.4 months (interquartile range, 13.3-49.7 months), during which 21 patients ( 12 in the minithoracotomy group and 9 in the sternotomy group) experienced significant MR $(>2+)$. Freedom from significant MR at 5 years was $86.1 \% \pm 4.8 \%$ versus $85.3 \% \pm 5.5 \%$ $(P=.63)$. After adjustment, the minithoracotomy group had similar risks for significant MR (hazard ratio, $0.81 ; 95 \%$ confidence interval, $0.31-2.14 ; P=.67$ ).

Conclusions: A minithoracotomy approach for MV repair showed comparable clinical outcomes and efficacy to conventional sternotomy for MV repair. (J Thorac Cardiovasc Surg 2014;147:1547-52)

Minimally invasive cardiac surgery (MICS) techniques for mitral valve (MV) repair have advanced during the past decade, and favorable results have been reported. Several single institutional studies have shown excellent clinical outcomes of the MICS approach, such as comparable short- and longterm mortality/morbidity, reduced sternal complications, and shortening of duration of ventilation and intensive care unit (ICU) and hospital stays. ${ }^{1-5} \mathrm{~A}$ recent consensus statement of the International Society of Minimally Invasive Surgery 2010 also documented that MICS enables complex valve surgery to be performed, with results equivalent to those of conventional valve surgery in experienced centers ${ }^{6}$; a systemic review of the literature with a meta-analysis of all important series has been published. ${ }^{7}$ However, limited data have been available regarding

From the Department of Thoracic and Cardiovascular Surgery, Asan Medical Center, University of Ulsan, College of Medicine, Seoul, South Korea.

Disclosures: Authors have nothing to disclose with regard to commercial support.

Received for publication March 13, 2013; revisions received April 24, 2013; accepted for publication May 10, 2013; available ahead of print July 15, 2013.

Address for reprints: Jae Won Lee, MD, PhD, Department of Thoracic and Cardiovascular Surgery, Asan Medical Center, University of Ulsan, College of Medicine, 88 Olympic-ro 43-gil, Songpa-gu, Seoul 138-736, South Korea (E-mail: jwlee@amc. seoul.kr).

0022-5223/\$36.00

Crown Copyright $\subset 2014$ Published by Elsevier Inc. on behalf of The American Association for Thoracic Surgery

http://dx.doi.org/10.1016/j.jtcvs.2013.05.042 the long-term efficacy of MV repair performed with MICS techniques. Although there have been several reports focused on comparing the long-term freedom from reoperation between MICS and sternotomy, few studies demonstrated the long-term quality of the repaired MV (regurgitation or stenosis) and freedom from significant MR based on long-term regular echocardiographic follow-up. ${ }^{8-10}$ In addition, previous studies have limitations for comparing outcomes between 2 groups, with significant differences in baseline characteristics. We, therefore, sought to compare the longterm clinical and echocardiographic outcomes of MV repair performed through a minithoracotomy versus a traditional sternotomy in a homogeneous population with degenerative MR using inverse-probability-of-treatment weighting (IPTW) to reduce baseline differences.

\section{METHODS \\ Study Population}

From April 2004 to January 2010, a total of 544 patients underwent MV repair for degenerative MR at Asan Medical Center (Seoul, Korea). Patients with combined aortic valve diseases, coronary diseases, and aortic diseases were excluded. Patients who underwent previous cardiac surgery were also excluded. However, patients with combined tricuspid regurgitation or atrial fibrillation (AF) were not excluded. Finally, a total of 299 patients who underwent MV repair for degenerative MR, with or without concomitant tricuspid annuloplasty or AF ablation, were identified and 


$$
\begin{aligned}
& \text { Abbreviations and Acronyms } \\
& \text { AF }=\text { atrial fibrillation } \\
& \text { ICU }=\text { intensive care unit } \\
& \text { IPTW }=\text { inverse-probability-of-treatment weighting } \\
& \text { LA }=\text { left atrial } \\
& \text { MICS }=\text { minimally invasive cardiac surgery } \\
& \text { MR }=\text { mitral regurgitation } \\
& \text { MV }=\text { mitral valve }
\end{aligned}
$$

which included thromboembolism, reoperation, infective endocarditis, or warfarin-related hemorrhage.

\section{Statistical Analysis}

Categorical variables were presented as frequencies and percentages, and continuous variables were expressed as mean $\pm \mathrm{SD}$ or medians with ranges. Differences in baseline characteristics between patients in the minithoracotomy group and those in the sternotomy group were compared using the $t$-test or the Mann-Whitney $U$ test for continuous variables and the $\chi^{2}$ test or Fisher exact test for categorical variables, as appropriate. To reduce the impact of treatment selection bias and potential confounding in an observational study, we performed rigorous adjustment for significant differences in patient characteristics by using Cox proportional-hazards regression models and IPTW. ${ }^{14-16}$ With this technique, weights for patients undergoing MV repair through a minithoracotomy were the inverse of propensity score, and weights for patients with conventional sternotomy were the inverse of 1 - propensity score. Stabilized weights were used to reduce the weights of either those treated subjects with low propensity scores or those untreated subjects with high propensity scores. ${ }^{17}$ The propensity scores were estimated by multiple logistic regression analysis. ${ }^{14}$ All prespecified covariates were included in full nonparsimonious models for the minithoracotomy group versus the sternotomy group (Table 1). The discrimination and calibration abilities of each propensity score model were assessed by $\mathrm{C}$ statistics and the Hosmer-Lemeshow test. The model was well calibrated (Hosmer-Lemeshow test, $P=.12$ ) with reasonable discrimination (C statistic, 0.73). Results were expressed as hazard ratio (HR) with $95 \%$ confidence intervals. All reported $P$ values are 2 sided, and values of $P<.05$ were considered to indicate statistical significance. All statistical analyses were performed using SPSS, version 18.0 (IBM, Armonk, NY) and R, version 2.15.1 (http://www.r-project.org).

\section{RESULTS \\ Baseline Characteristics and Operative Data}

Baseline characteristics of the patients are shown in Table 1. Before adjustment, the proportions of preoperative New York Heart Association classification III/IV, AF, and significant tricuspid regurgitation were higher in the sternotomy group. Preoperative LA dimension and estimated pulmonary artery systolic pressure (tricuspid valve pressure gradient) were also higher in the sternotomy group. After adjustment with the use of IPTW, the significant differences in baseline characteristics between the 2 groups were well balanced (Table 1).

The cardiopulmonary bypass time was $131.7 \pm 38.5$ minutes in the minithoracotomy group and $126.6 \pm 43.2$ minutes in the sternotomy group $(P=.30)$, and the aortic crossclamp times were $84.3 \pm 28.7$ and $80.5 \pm 32.0$ minutes, respectively $(P=.39)$. Concomitant maze procedures were conducted in $24.6 \%$ of patients in the minithoracotomy group and in $32.5 \%$ of patients in the sternotomy group $(P=.15)$. Except for the performance of concomitant tricuspid annuloplasty, other operative variables were not significantly different (Table 2).

\section{Clinical Outcomes}

There were no early deaths in either group and no differences in immediate postoperative complications (Table 3 ). The lengths of hospital stay and ICU stay of the 


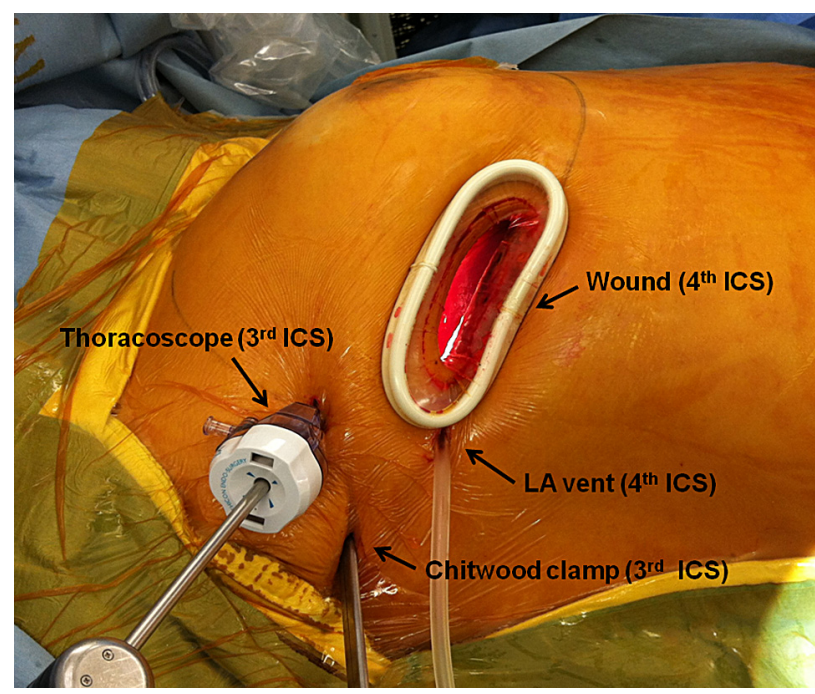

FIGURE 1. A 4- to 5-cm right inframmammary skin incision and right fourth intercostal space minithoracotomy in a female patient and other sites for thoracoscopy. The chitwood clamp and left atrial vent are shown. ICS, Intercostal space; $L A$, left atrial.

minithoracotomy group were significantly shorter than those of the sternotomy group $(P=.039$ and $P=.012$, respectively).
Clinical follow-up was complete in 294 patients $(98.3 \%)$, with a median follow-up of 55.4 months (interquartile range, 34.4-66.9 months), during which there were 10 late deaths, 2 cases of stroke, and 3 cases of reoperation. Two cases of reoperation were due to recurrent MR, and the other one was due to dilated cardiomyopathy. There was no mitral stenosis. Major event-free survival at 5 years was $97.6 \% \pm 1.2 \%$ in the minithoracotomy group and $87.5 \% \pm 4.9 \%$ in the sternotomy group $(P=.046)$ (Figure 2, left). However, after adjustment with weighted Cox regression analysis, both groups had comparable event-free survival (HR, $0.77 ; 95 \%$ confidence interval, $0.22-2.68 ; P=.68$ ) (Figure 2, right)

\section{Echocardiographic Outcomes}

Echocardiographic evaluation was possible in 292 patients $(97.7 \%)$, with a median follow-up of 29.4 months (interquartile range, 13.3-49.7 months), during which 21 patients (12 in the minithoracotomy group and 9 in the sternotomy group; $P=.72$ ) experienced significant $\mathrm{MR}$ $(>2+)$. Freedom from significant MR $(>2+)$ at 5 years was $86.1 \% \pm 4.8 \%$ versus $85.3 \% \pm 5.5 \%$ in the minithoracotomy versus sternotomy group, respectively $(P=.19)$

TABLE 1. Baseline patient profiles $(N=299)$

\begin{tabular}{|c|c|c|c|c|c|c|}
\hline \multirow[b]{2}{*}{ Characteristics } & \multicolumn{3}{|c|}{ Unadjusted data* } & \multicolumn{3}{|c|}{ Data adjusted with the use of IPTW $\dagger$} \\
\hline & $\begin{array}{l}\text { Minithoracotomy } \\
(\mathbf{n}=179)\end{array}$ & $\begin{array}{l}\text { Sternotomy } \\
(\mathbf{n}=\mathbf{1 2 0})\end{array}$ & $P$ value & $\begin{array}{l}\text { Minithoracotomy } \\
(\mathbf{n}=\mathbf{1 7 9})\end{array}$ & $\begin{array}{l}\text { Sternotomy } \\
(\mathbf{n}=\mathbf{1 2 0})\end{array}$ & $P$ value \\
\hline \multicolumn{7}{|l|}{ Demography } \\
\hline Male sex & $111(62.0)$ & $79(65.8)$ & .50 & 62.0 & 65.8 & .50 \\
\hline Age, y & $48.9 \pm 14.1$ & $56.6 \pm 13.2$ & .14 & $51.8 \pm 13.7$ & $52.1 \pm 14.8$ & .84 \\
\hline Body surface area, $\mathrm{m}^{2}$ & $1.7 \pm 0.2$ & $1.7 \pm 0.2$ & .45 & $1.7 \pm 0.2$ & $1.7 \pm 0.2$ & .22 \\
\hline \multicolumn{7}{|l|}{ Clinical data } \\
\hline NYHA Fc III or IV & $39(21.8)$ & $60(50)$ & $<.001$ & 34.5 & 37.2 & .12 \\
\hline Atrial fibrillation & $45(25.2)$ & $46(32.5)$ & .021 & 29.1 & 29.2 & .98 \\
\hline Hypertension & $57(31.8)$ & $48(40)$ & .15 & 36.3 & 35.0 & .82 \\
\hline Diabetes mellitus & $8(4.5)$ & $12(10)$ & .061 & 6.7 & 6.7 & .99 \\
\hline History of stroke & $1(0.6)$ & $3(2.5)$ & .15 & 1.7 & 1.7 & .99 \\
\hline \multicolumn{7}{|l|}{ Echocardiographic data } \\
\hline LV ejection fraction, $\%$ & $61.6 \pm 7.3$ & $61.5 \pm 8.5$ & .95 & $61.8 \pm 7.2$ & $61.7 \pm 7.8$ & .89 \\
\hline LV systolic dimension, $\mathrm{mm}$ & $38.8 \pm 6.4$ & $39.9 \pm 7.9$ & .48 & $37.7 \pm 6.7$ & $39.0 \pm 7.4$ & .76 \\
\hline $\mathrm{LV}$ diastolic dimension, $\mathrm{mm}$ & $60.8 \pm 6.7$ & $62.1 \pm 7.7$ & .50 & $60.8 \pm 7.3$ & $61.2 \pm 7.5$ & .62 \\
\hline LA dimension, $\mathrm{mm}$ & $49.9 \pm 8.9$ & $55.0 \pm 11.8$ & .001 & $50.9 \pm 9.1$ & $51.5 \pm 11.3$ & .65 \\
\hline TR grade $(>2+)$ & $13(7.3)$ & $25(20.8)$ & .001 & 11.7 & 12.5 & .84 \\
\hline $\mathrm{TV}$ pressure gradient, $\mathrm{mmHg}$ & $33.8 \pm 15.8$ & $40.0 \pm 17.2$ & .002 & $36.2 \pm 17.3$ & $37.1 \pm 17.6$ & .67 \\
\hline MR grade & & & .80 & & & .33 \\
\hline Severe & $168(93.9)$ & $114(95)$ & & 93.9 & 90.8 & \\
\hline Moderate to severe & $11(6.1)$ & $6(5)$ & & 6.1 & 9.2 & \\
\hline \multicolumn{7}{|l|}{ MV leaflet prolapse subsets } \\
\hline Anterior leaflet & $30(16.8)$ & $16(13.3)$ & .42 & 14.0 & 14.2 & .96 \\
\hline Bileaflet & $30(16.8)$ & $37(30.8)$ & .005 & 23.5 & 25.0 & .78 \\
\hline Posterior leaflet & $119(66.5)$ & $67(55.8)$ & .069 & 62.6 & 60.8 & .76 \\
\hline
\end{tabular}

IPTW, Inverse-probability-of-treatment weighting; NYHA $F c$, New York Heart Association functional class; $L V$, left ventricle; $L A$, left atrium; $T R$, tricuspid regurgitation; $T V$, tricuspid valve; $M R$, mitral regurgitation; $M V$, mitral valve. $*$ Value are given as number $(\%)$ or mean $\pm \mathrm{SD}$. $\dagger$ Values are given as $\%$ or mean $\pm \mathrm{SD}$. 
TABLE 2. Operative characteristics

\begin{tabular}{lccc}
\hline \multicolumn{1}{c}{ Variable } & $\begin{array}{c}\text { Minithoracotomy } \\
(\mathbf{n}=\mathbf{1 7 9})\end{array}$ & $\begin{array}{c}\text { Sternotomy } \\
(\mathbf{n}=\mathbf{1 2 0})\end{array}$ & $\boldsymbol{P}$ value \\
\hline Bypass time, min & $131.6 \pm 38.5$ & $126.6 \pm 43.2$ & .30 \\
Crossclamp time, min & $84.3 \pm 28.7$ & $80.5 \pm 32.0$ & .39 \\
Maze procedure & $44(24.6)$ & $39(32.5)$ & .15 \\
Concomitant TAP & $23(12.8)$ & $35(29.2)$ & .001 \\
Mitral repair procedure & & & \\
$\quad$ Ring annuloplasty & $179(100)$ & $120(100)$ & \\
Quadrangular/triangular & $103(57.5)$ & $71(59.2)$ & .81 \\
$\quad$ resection & & & \\
Artificial chordate & $60(33.5)$ & $32(26.7)$ & .25 \\
Commissuroplasty & $33(18.4)$ & $26(21.7)$ & .55 \\
$\quad$ Alfieri & $8(4.5)$ & $4(3.3)$ & .77 \\
Chordal transfer or & $7(3.9)$ & $5(4.2)$ & .91 \\
$\quad$ shortening & & & \\
$\quad$ Leaflet plication & $3(1.7)$ & $7(5.8)$ & .10 \\
Leaflet manipulation & & & \\
$\quad$ Anterior leaflet & $46(25.7)$ & $41(34.2)$ & .11 \\
$\quad$ Posterior leaflet & $104(58.1)$ & $68(56.7)$ & .81 \\
Bileaflet & $28(15.6)$ & $10(8.3)$ & .063 \\
\hline Values are given as number $(\%)$ or mean + SD. TAP. Tricuspid annuloplasty.
\end{tabular}

Values are given as number $(\%)$ or mean $\pm \mathrm{SD}$. TAP, Tricuspid annuloplasty.

(Figure 3, left). After adjustment using weighted Cox regression analysis, both groups had comparable freedom from significant MR $(>2+)$ (HR, $0.81 ; 95 \%$ confidence interval, 0.31-2.14; $P=.67$ ) (Figure 3, right).

TABLE 3. Postoperative outcomes' comparison between the minithoracotomy group and the sternotomy group

\begin{tabular}{lccc}
\hline \multicolumn{1}{c}{ Variable } & $\begin{array}{c}\text { Minithoracotomy Sternotomy } \\
(\mathbf{n}=\mathbf{1 7 9})\end{array}$ & $(\mathbf{n}=\mathbf{1 2 0})$ & $\boldsymbol{P}$ value \\
\hline Early death $(<30 \mathrm{~d})$ & $0(0)$ & $0(0)$ & \\
Hospital stay, $\mathrm{d}^{*}$ & $6(5-8)$ & $9(7-14)$ & .039 \\
ICU stay, $\mathrm{h}^{*}$ & $28(22-47)$ & $47(30-72)$ & .012 \\
Complications & & & \\
$\quad$ Reoperations for bleeding & $3(1.7)$ & $4(3.3)$ & .35 \\
ARF requiring dialysis & $1(0.6)$ & $1(0.8)$ & .78 \\
$\quad$ Low cardiac output & $0(0)$ & $0(0)$ & \\
Stroke & $0(0)$ & $2(1.7)$ & .084 \\
Permanent pacemaker & $0(0)$ & $1(0.8)$ & .22 \\
$\quad$ insertion & & & \\
$\quad$ Thromboembolic event & $0(0)$ & $0(0)$ & \\
Reoperations for MR & $2(1.1)$ & $1(0.8)$ & $>.99$ \\
Late mortality & $4(2.2)$ & $6(5)$ & .19 \\
Last echocardiographic data & & & \\
$\quad>6$ mo) (n = 292) $\dagger$ & & & \\
$\quad$ LV ejection fraction, \% & $59.3 \pm 6.9$ & $58.4 \pm 7.4$ & .35 \\
LV systolic dimension, mm & $32.4 \pm 5.8$ & $32.7 \pm 7.3$ & .76 \\
LV diastolic dimension, mm & $49.9 \pm 5.2$ & $50.1 \pm 6.6$ & .82 \\
LA dimension, mm & $42.4 \pm 5.2$ & $45.1 \pm 8.9$ & .031 \\
TV pressure gradient, mmHg & $23.4 \pm 6.5$ & $24.5 \pm 7.2$ & .22 \\
\hline
\end{tabular}

Values are given as number ( $\%$ ) or mean \pm SD. ICU, Intensive care unit; $A R F$, acute renal failure; $M R$, mitral regurgitation; $L V$, left ventricular; $L A$, left atrial; $T V$, tricuspid valve. $*$ Values are given as the median (interquartile range). $\dagger$ Adjusted with the use of inverse-probability-of-treatment weighting.

\section{DISCUSSION}

Since MICS was introduced in the 1990s, its advantages, such as early postoperative recovery, better respiratory tract function, better cosmetic results, and less pain and bleeding, have been widely accepted. Current guidelines predicate early referral for MV repair in asymptomatic patients on the ability to offer complete anatomic correction, with greater than $90 \%$ certainty accompanied by low morbidity and mortality rates. ${ }^{18}$ Asymptomatic or minimally symptomatic patients may seek to avoid traditional surgical incisions when less invasive options are possible, hoping to minimize the length of temporary postoperative disability. ${ }^{19}$ However, there must be the prerequisites for minimally invasive MV repair: completeness of surgical correction, safety, and good or at least equivalent outcomes compared with conventional sternotomy.

Although minimally invasive MV repair has been considered to be a feasible alternative to the conventional full sternotomy approach, with low perioperative morbidity and mortality and with several studies reporting on acceptable early and long-term outcomes, ${ }^{2,3,7}$ its active use is limited to few centers in South Korea. This may be attributable to the concerns about the increased operative risk and complications, the long learning curve, and relatively low cost-effectiveness as the result of the high price of the MICS equipment. ${ }^{20}$ Most important, the major concerns are related to potential limitations in using the various MV repair techniques and the competence required for MV repair with the use of MICS equipment.

To determine whether MICS for MV repair is feasible, the effectiveness of the MV repair technique itself and the maintenance of MV function must be assessed throughout the late period. For this reason, our study focused on the recurrence of significant MR after surgery, and we observed no statistical differences in the long-term recurrence rate of MR between conventional sternotomy and minithoracotomy (Figure 3). In support of our results, a recent study also demonstrated no difference in the proportion of patients with MR grade $3+$ or $4+$ at 1 and 5 years after minithoracotomy when compared with the sternotomy approach. ${ }^{5} \mathrm{Al}-$ though there have been several reports comparing the longterm outcomes between MICS and sternotomy, few studies demonstrated the long-term quality of the repaired MV and freedom from significant MR. Raanani and colleagues ${ }^{8}$ reported late echocardiographic analysis comparing MR repair through the port-access versus the median sternotomy approach in isolated posterior MV pathology, which revealed $91 \%$ versus $82 \%$ freedom from moderate or greater MR at 5 years $(P=.90)$. Our data showed a low reoperation rate for the MV problem $(1.1 \%$ in the minithoracotomy group and $0.8 \%$ in the sternotomy group) and favorable freedom from significant MR at 5 years $(86.1 \%$ vs $85.3 \%$ ), with no statistical difference between the 2 groups 

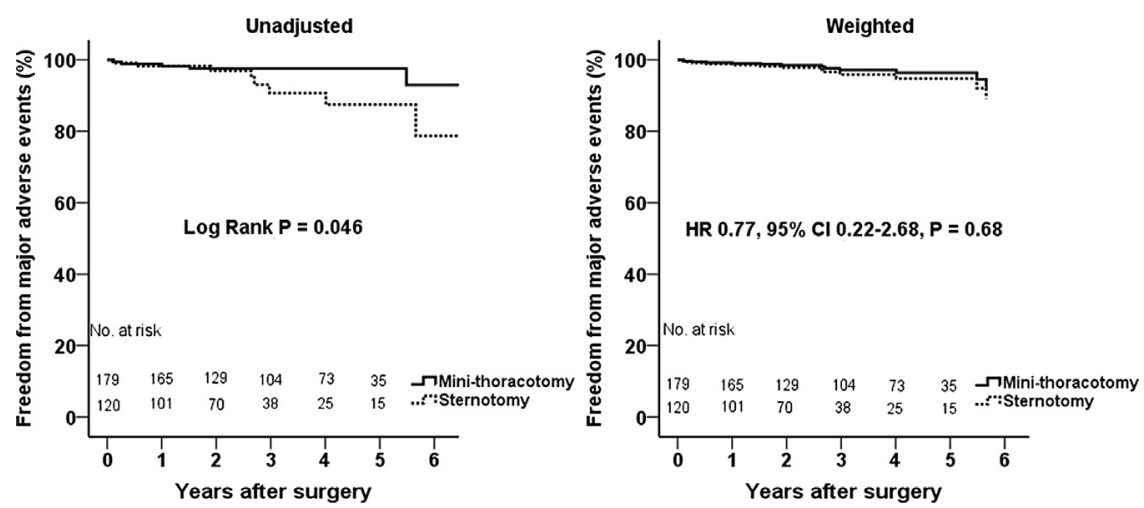

FIGURE 2. Freedom from major event or death. $H R$, Hazard ratio; $C I$, confidence interval.

$(P=.67)$. Furthermore, significant findings of the current study indicated that there was a relatively greater portion of anterior MV pathology in the patient population (33.5\% in the minithoracotomy group and $44.2 \%$ in the sternotomy group), and the various MV repair techniques were used in the 2 groups without showing any statistical difference (Table 2).

Another advantage of the thoracotomy approach for MV surgery is better MV exposure. A right lateral minithoracotomy for MV exposure allows a direct view of the posteriorly positioned MV, including the valvular and subvalvular apparatus, without a significant amount of tissue dissection or distortion of the heart. ${ }^{21}$ Even when an implanted AV exists, the MV approach and manipulation are easier with a thoracotomy approach without removal of the prosthetic AV. Minimally invasive MV reoperation is also a useful alternative for patients requiring a MV procedure after a previous cardiac operation. ${ }^{21} \mathrm{Car}-$ diac reoperation for MV generally has a higher risk of morbidity and mortality than the first operation, particularly for the MV anatomic position. ${ }^{22}$ A sternotomy approach with extensive pericardial adhesions carries a higher risk of major vessel injury and the danger of injuring a previous patent coronary artery bypass graft. The thoracotomy approach can give excellent exposure of the $\mathrm{MV}$, good myocardial protection, and decreased risk of major vascular injury, resulting in less perioperative bleeding, lower transfusion requirements, and lower operative mortality. ${ }^{23,24}$ Recent studies have reported that MICS is cost-effective because of reduced bleeding and shorter ICU and hospital stays. ${ }^{25,26}$

\section{Study Limitations}

This study is subject to the limitations inherent to retrospective observational data studies, and the study population is relatively small compared with that of the international data. As previously mentioned, the small numbers were mainly due to the fact that port-access minimally invasive MV surgery is still limited to only several centers in Korea.

\section{CONCLUSIONS}

In conclusion, a minithoracotomy approach for MV repair showed comparable clinical and echocardiographic outcomes to the conventional sternotomy approach. Furthermore, minimally invasive MV repair is efficacious and feasible.
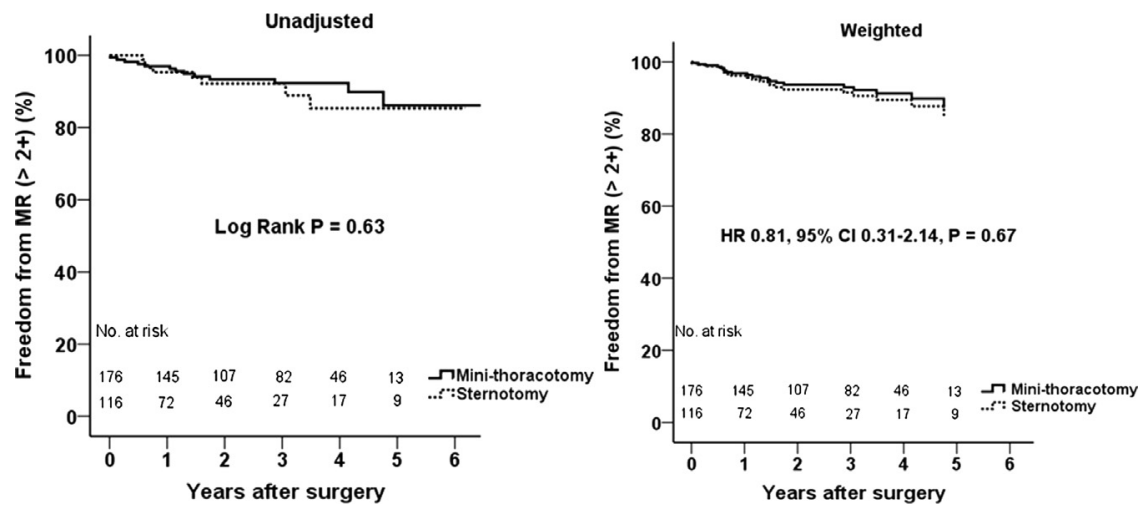

FIGURE 3. Freedom from moderate or greater mitral regurgitation $(M R)$. $H R$, Hazard ratio; $C I$, confidence interval. 
We thank Sung-Cheol Yun, $\mathrm{PhD}$, for his efforts on reviewing the statistical methods used in this study.

\section{References}

1. Iribarne A, Russo MJ, Easterwood R, Hong KN, Yang J, Cheema FH, et al. Minimally invasive versus sternotomy approach for mitral valve surgery: a propensity analysis. Ann Thorac Surg. 2010;90:1471-7; discussion 77-8.

2. Greelish JP, Cohn LH, Leacche M, Mitchell M, Karavas A, Fox J, et al. Minimally invasive mitral valve repair suggests earlier operations for mitral valve disease. J Thorac Cardiovasc Surg. 2003;126:365-71; discussion 71-3.

3. McClure RS, Cohn LH, Wiegerinck E, Couper GS, Aranki SF, Bolman RM III, et al. Early and late outcomes in minimally invasive mitral valve repair: an eleven-year experience in 707 patients. $J$ Thorac Cardiovasc Surg. 2009;137: 70-5.

4. Galloway AC, Schwartz CF, Ribakove GH, Crooke GA, Gogoladze G, Ursomanno P, et al. A decade of minimally invasive mitral repair: long-term outcomes. Ann Thorac Surg. 2009;88:1180-4.

5. Svensson LG, Atik FA, Cosgrove DM, Blackstone EH, Rajeswaran J, Krishnaswamy G, et al. Minimally invasive versus conventional mitral valve surgery: a propensity-matched comparison. J Thorac Cardiovasc Surg. 2010;139: 926-32, e1-2.

6. Falk V, Cheng DC, Martin J, Diegeler A, Folliguet TA, Nifong LW, et al. Minimally invasive versus open mitral valve surgery: a consensus statement of the International Society of Minimally Invasive Coronary Surgery (ISMICS) 2010. Innovations (Phila). 2011;6:66-76.

7. Modi P, Hassan A, Chitwood WR Jr. Minimally invasive mitral valve surgery: a systematic review and meta-analysis. Eur J Cardiothorac Surg. 2008;34: 943-52.

8. Raanani E, Spiegelstein D, Sternik L, Preisman S, Moshkovitz Y, Smolinsky AK, et al. Quality of mitral valve repair: median sternotomy versus port-access approach. J Thorac Cardiovasc Surg. 2010;140:86-90.

9. Grossi EA, LaPietra A, Ribakove GH, Delianides J, Esposito R, Culliford AT, et al. Minimally invasive versus sternotomy approaches for mitral reconstruction: comparison of intermediate-term results. J Thorac Cardiovasc Surg. 2001;121: 708-13.

10. Cheng DC, Martin J, Lal A, Diegeler A, Folliguet TA, Nifong LW, et al. Minimally invasive versus conventional open mitral valve surgery: a meta-analysis and systematic review. Innovations (Phila). 2011;6:84-103.

11. Felger JE, Chitwood WR Jr, Nifong LW, Holbert D. Evolution of mitral valve surgery: toward a totally endoscopic approach. Ann Thorac Surg. 2001;72:1203-8; discussion 1208-9.

12. Lee JW, Choo SJ, Kim KI, Song JK, Kang DH, Song JM, et al. Atrial fibrillation surgery simplified with cryoablation to improve left atrial function. Ann Thorac Surg. 2001;72:1479-83.
13. Miyatake K, Izumi S, Okamoto M, Kinoshita N, Asonuma H, Nakagawa H, et al. Semiquantitative grading of severity of mitral regurgitation by real-time twodimensional Doppler flow imaging technique. J Am Coll Cardiol. 1986;7:82-8.

14. Normand SL. Evaluating the optimal timing of angiography: landmark or off the mark? Circulation. 2007;116:2656-7.

15. Robins JM, Hernan MA, Brumback B. Marginal structural models and causal inference in epidemiology. Epidemiology. 2000;11:550-60.

16. Platt RW, Delaney JAC, Suissa S. The positivity assumption and marginal structural models: the example of warfarin use and risk of bleeding. Eur J Epidemiol. 2012;27:77-83

17. Xu S, Ross C, Raebel MA, Shetterly S, Blanchette C, Smith D. Use of stabilized inverse propensity scores as weights to directly estimate relative risk and its confidence intervals. Value Health. 2010;13:273-7.

18. Bonow RO, Carabello BA, Chatterjee K, de Leon AC Jr, Faxon DP, Freed MD, et al. 2008 Focused update incorporated into the ACC/AHA 2006 guidelines for the management of patients with valvular heart disease: a report of the American College of Cardiology/American Heart Association Task Force on Practice Guidelines (Writing Committee to revise the 1998 guidelines for the management of patients with valvular heart disease): endorsed by the Society of Cardiovascular Anesthesiologists, Society for Cardiovascular Angiography and Interventions, and Society of Thoracic Surgeons. J Am Coll Cardiol. 2008;52: e1-142.

19. Suri RM, Burkhart HM, Daly RC, Dearani JA, Park SJ, Sundt TM, et al. Robotic mitral valve repair for all prolapse subsets using techniques identical to open valvuloplasty: establishing the benchmark against which percutaneous interventions should be judged. J Thorac Cardiovasc Surg. 2011;142:970-9.

20. Loulmet DF, Carpentier A, Cho PW, Berrebi A, d'Attellis N, Austin CB, et al. Less invasive techniques for mitral valve surgery. J Thorac Cardiovasc Surg. 1998;115:772-9.

21. Seeburger J, Borger MA, Falk V, Passage J, Walther T, Doll N, et al. Minimally invasive mitral valve surgery after previous sternotomy: experience in 181 patients. Ann Thorac Surg. 2009;87:709-14.

22. Akins CW, Buckley MJ, Daggett WM, Hilgenberg AD, Vlahakes GJ, Torchiana DF, et al. Risk of reoperative valve replacement for failed mitral and aortic bioprostheses. Ann Thorac Surg. 1998;65:1545-51; discussion 51-2.

23. Burfeind WR, Glower DD, Davis RD, Landolfo KP, Lowe JE, Wolfe WG. Mitral surgery after prior cardiac operation: port-access versus sternotomy or thoracotomy. Ann Thorac Surg. 2002;74:S1323-5.

24. Bolotin G, Kypson AP, Reade CC, Chu VF, Freund WL Jr, Nifong LW, et al. Should a video-assisted mini-thoracotomy be the approach of choice for reoperative mitral valve surgery? J Heart Valve Dis. 2004;13:155-8; discussion 158.

25. Iribarne A, Easterwood R, Russo MJ, Wang YC, Yang J, Hong KN, et al. A minimally invasive approach is more cost-effective than a traditional sternotomy approach for mitral valve surgery. J Thorac Cardiovasc Surg. 2011;142:1507-14.

26. Kam JK, Cooray SD, Kam JK, Smith JA, Almeida AA. A cost-analysis study of robotic versus conventional mitral valve repair. Heart Lung Circ. 2010;19:413-8. 